\title{
Differences in floral development between Lycoris radiata and Lycoris sprengeri
}

\author{
Junhuo Cai ${ }^{\mathrm{a}, \uparrow}$, Junjun Fan ${ }^{\mathrm{b}, \uparrow}$, Xuying Wei ${ }^{\mathrm{c}}$, Donglin Zhang ${ }^{\mathrm{d}}$, Jiajia Ren ${ }^{\mathrm{a}}$, Lu Zhang, ${ }^{\mathrm{a}, \mathrm{e}, *}$ \\ a College of Landscape and Art, Jiangxi Agricultural University, Nanchang 330045 China \\ b College of Horticulture, Jinling Institute of Technology, Nanjing 210037 China \\ c College of Art, Jiangxi Finance and Economics University, Nanchang 330032 China \\ d Department of Horticulture, University of Georgia, Athens, GA 30602 USA \\ e Collaboration Innovation Center of Jiangxi Typical Trees Cultivation and Utilization, Jiangxi \\ Agricultural University, Nanchang 330045 China
}

*Corresponding author, e-mail: zhlu856@163.com, Cai J. and Fan J. contributed equally to this paper.

Received 12 Sep 2019

Accepted 21 Mar 2020

\begin{abstract}
Lycoris radiata and Lycoris sprengeri are two typical plants of the genus Lycoris. They have different leafing and flowering patterns. To understand the habits of Lycoris species and regulate the flowering period effectively, we compared flower bud development of these two species using phenological, anatomical, and physiological measurements. Our results showed there were significant differences in phenology between the two species. The sprouting stage of $L$. radiata took place in autumn, the leaf growth period lasted seven months, dormancy lasted approximately 100 days before flowering, and there was no dormancy period after flowering. In comparison, the sprouting period of $L$. sprengeri was delayed until the spring of the following year, the leaf growth stage lasted approximately 3 months, the flowering stage took place from Jul-Aug, and dormancy lasted 1-2 months before flowering and for another 6 months after flowering. The flower bud differentiation processes of the two species were similar. During the entire flower bud differentiation process, the soluble sugar and protein contents, as well as the superoxide dismutase activity, in $L$. sprengeri bulbs were significantly higher than in $L$. radiata bulbs, whereas peroxidase activity was significantly lower.
\end{abstract}

KEYWORDS: phenology, flower bud differentiation, flower development

\section{INTRODUCTION}

There are 20 species of genus Lycoris worldwide. Lycoris plants are unique herbs in Southeast Asia, and are mainly produced in China (15 species, 2 varieties) and Japan; few are grown in Burma and North Korea [1,2]. Around 10 species are widely used in gardening and medicine [3]. There are 12 species that are unique to China [4], which are commonly found south of the Yangtze River and consist primarily of temperate species [3]. Lycoris plants have diverse flower colors and bloom in midsummer or early autumn. In addition, these plants are tolerant to drought and nutrient deficiency and are also less sensitive to pests and diseases. Therefore, these plants are superior materials for bulb flowers and ground cover in gardens. Breeding work of Lycoris plants started in the 1940s in various countries, but the first hybrid L. elegans (L. sprengeri $\times$ L. chinensis) was obtained in China in the 1970s [1]. In recent years, the study of Lycoris has promoted its production and use in gardening, and $368 \mathrm{hm}^{2}$ of L. radiata have been artificially cultivated in Jiangxi [5].

The life cycle of Lycoris plants can be divided into aboveground and underground stages. The aboveground stages include flowering and leaf sprouting [2], whereas the underground stages are dominated by bulb growth and dormancy. Lycoris plants are divided into two types based on autumn sprouting (mid-end Oct) or spring sprouting (early Feb). In general, L. radiata (L'Hér.) Herb. is the type of sprouting, which blooms in early autumn [6]. L. sprengeri Comes Ex Baker is thought to be the type of spring sprouting, which blooms in summer. However, other studies have found that the leaves of $L$. sprengeri continue to emerge from autumn to spring (the percentage of leave-sprouting seedlings in autumn was less than $50 \%$, and then they continued to emerge in the following spring). Leaf bud 
differentiation in Lycoris plants begins around the end of Mar and is completed in Sep. The flower bud differentiation processes of the two types of Lycoris plants are generally similar. Flower bud differentiation occurs in underground bulbs in Lycoris plants, during which almost no leaves are present. The starting time of flower bud differentiation in Lycoris plants is easily affected by environmental factors such as temperature. For this reason, various researchers have identified different distinguishing features for the flower bud differentiation stage in the same plants [6].

Despite the increase in the number of studies on the regulation of flowering in Lycoris plants, systematic investigations on flower development are still limited. The present study conducted a comparative analysis of the phenological characteristics, morphological anatomy-related characteristics of flower bud differentiation, and physiological characteristics of flower development for two species of different sprouting types: $L$. radiata and $L$. sprengeri. The results of this study may serve as a foundation for future studies on the hybridization and breeding of Lycoris plants, as well as provide insight for understanding the diversity of growth rhythms and for investigations on the regulation of flowering in Lycoris plants.

\section{MATERIALS AND METHODS}

\section{Overview of study materials and site}

L. radiata (L'Hér.) Herb. and L. sprengeri Comes Ex Baker were obtained from the experimental flower nursery in Jiangxi Agricultural University (Nanchang, China, $28.76^{\circ} \mathrm{N}, 115.83^{\circ} \mathrm{E}$ ). L. radiata generates quadrennial bulbs, which are obtained by asexual reproduction and have a diameter of $3.5 \pm 0.1 \mathrm{~cm}$. The soil used was red soil that was developed from Quaternary red clay parent material. In the $0-40 \mathrm{~cm}$ soil layer, the particle distribution was as follows: $12.12,51.63,35.87$, and $0.38 \%$ for soil depths of $<0.002,0.002-0.05,0.05-2.00$, and $>2.00 \mathrm{~mm}$, respectively. Soil organic matter content was $13.5 \mathrm{~g} / \mathrm{kg}$. Soil nitrogen, phosphorus, and potassium contents were $0.84,0.24$, and $24.9 \mathrm{~g} / \mathrm{kg}$ respectively, and the $\mathrm{pH}$ was 6.43 .

\section{Experimental methods}

\section{Phenological observations}

Fixed plant observations were performed; 5 observation points for each species were used. The area of each observation point was $300 \times 300 \mathrm{~cm}^{2}$, and 300 Lycoris plants were planted. The row spacing was $15 \mathrm{~cm} \times 20 \mathrm{~cm}$. Five sampling points in every observation point were used to select 5 plants for observation and recording of phenological traits during the entire growth period [7]. Photographs of the plants were obtained (from leaf sprouting to flower withering).

The phenological record cycle was from 1 Sep 2013 to 20 Oct 2014. The plants were observed once every 5 days. The number of sprouted leaves, leaf length and width, leaf tip yellowing, leaf withering, leaf withered, scape emergence, scaping, flowering, and flower withering were recorded. The division criteria of different phenological periods were as follows. Leaf sprouting period was from $5 \%$ to $85 \%$ of the plants with sprouting leaves. Greening period was from $85 \%$ of the plants with sprouting leaves to $5 \%$ of the plants with yellow leaves. Defoliation period (leaf yellowing and withering) was from $5 \%$ of the plants with yellow leaves to $85 \%$ of the plants without leaves. Dormancy period (leafless) was from $85 \%$ of the plants without leaves to $5 \%$ of the plants with sprouting leaves or scape sprouting. Flowering period (scape sprouting and blooming) was from scape sprouting to flower withering.

\section{Paraffin sections of bulb shoots}

From 10 Mar-25 Jul 2014, L. radiata and L. sprengeri bulbs were collected once every 5 days for a total of five times. We randomly sampled 1 bulb at each observation point. The bulbs were collected regularly, and the central flower bud was removed and washed with deionized water before fixing in a mixed fixative solution $(90 \mathrm{ml}$ of $70 \%$ alcohol $+5 \mathrm{ml}$ glacial acetic acid $+5 \mathrm{ml}$ of formalin, FAA) for more than $24 \mathrm{~h}$. Routine paraffin sections $(8 \mu \mathrm{m}$ thick) were prepared for flower bud morphological observation [7], with slight modifications. The sections were stained with iron (II) sulfate-hematoxylin and examined and photographed using a stereoscopic microscope (DM2500, Leica, Germany).

\section{Physiological measurements of bulbs}

Nine Lycoris (triplicates, 3 plants per replicate) plants were randomly selected every 5 days and their bulbs were extracted. After washing with tap water and drying, the first 2-4 layers were removed, crushed, pooled, and used for measuring various physiological markers. Soluble sugar content was measured by anthrone colorimetry. Soluble protein content was determined using Coomassie blue (G- 
250) staining, and nitroblue tetrazolium (NBT) photoreduction was employed to measure superoxide dismutase (SOD) activity (1 enzyme unit (U) is equivalent to a $50 \%$ inhibition of NBT photoreduction). Peroxidase (POD) activity was measured using guaiacol colorimetry.

\section{Data analysis}

The mean and standard deviation of each marker was analyzed using Excel 2013. One-way ANOVA (Duncan's test) in SPSS 17.0 was used for the comparison of the same factor at different levels of significance $(p<0.01)$.

\section{RESULTS}

\section{Phenological characteristics of $L$. radiata and L. sprengeri}

The leaves of $L$. radiata are shaped like a narrow band, with a length of approximately $15 \mathrm{~cm}$ and width of $0.5 \mathrm{~cm}$. The tip of the leaf is blunt, and the leaf is dark green in color, with a pale green belt in the center. The height of the scape is $30 \mathrm{~cm}$. There are 2 bracts in total that are lanceolate-shaped, approximately $3.5 \mathrm{~cm}$ in length and $0.5 \mathrm{~cm}$ in width. There are 4-7 umbrellashaped inflorescences that are bright red in color. The perianth lobes are oblanceolate-shaped, with a length of $3.0 \mathrm{~cm}$ and width of $0.5 \mathrm{~cm}$, strongly wrinkled, and revoluted. The perianth is green in color and $0.5 \mathrm{~cm}$ in length. The stamens are significantly extended outside of the perianth and are one-fold longer than the perianth. The bulb is nearly spherical in shape. A mature bulb has a diameter of 3.2-3.5 cm. Nanchang has a subtropical humid monsoon climate with abundant sunshine (146150 days of sun per year), enough rainfall (1600$1700 \mathrm{~mm}$ and $147-157$ days of precipitation per year), warm springs $\left(11.8-23^{\circ} \mathrm{C}\right)$, burning hot summers $\left(26-29.6^{\circ} \mathrm{C}\right)$ and cold winters $\left(2.8-8.1^{\circ} \mathrm{C}\right)$, long summers and winters, and short springs and autumns $\left(13.9-25.3^{\circ} \mathrm{C}\right)$. In Nanchang, Aug-Sep is the flowering period and leaves start to sprout in Oct after the flowers have withered. The plants enter a dormant period in May of the following year after the leaves have defoliated.

The leaves of $L$. sprengeri are banded and are $30 \mathrm{~cm}$ in length, $1.0 \mathrm{~cm}$ in width, green in color, and have blunt tips. Scape height is approximately $60 \mathrm{~cm}$. There are 2 bracts that are $3.5 \mathrm{~cm}$ in length and $1.2 \mathrm{~cm}$ in width. There are 4-6 umbrellashaped inflorescences that are pale purplish-red in color. The tip of the petal lobes is often blue, and the petal lobes are oblanceolate-shaped, approximately $4.5 \mathrm{~cm}$ in length, $1.0 \mathrm{~cm}$ in width, and the edges are smooth. The length of the perianth tube is $1-1.5 \mathrm{~cm}$. The stamens are nearly as long as the perianth, and the style slightly extends outside the perianth. The capsule is trigonous and its fruits are dehiscent. The seeds are nearly spherical, have a diameter of $0.5 \mathrm{~cm}$, and are black in color. A mature bulb has a diameter of $3.5 \mathrm{~cm}$. The flowering period is usually in Jul-Aug, and leaves start to develop in Feb of the following year after dormancy. At the end of May, all leaves wither and the plants enter dormancy before flowering.

Compared to $L$. radiata, $L$. sprengeri has a later leaf sprouting period and an early flowering period. The dormancy period (around 1.5 month) before flowering as well as the greening period (around 2.5 months) are significantly shortened for $L$. sprengeri, but there is an additional dormancy period after flowering that lasts for five months. The differences in the growth patterns of the two species may be due to variations in adaptation strategies to similar

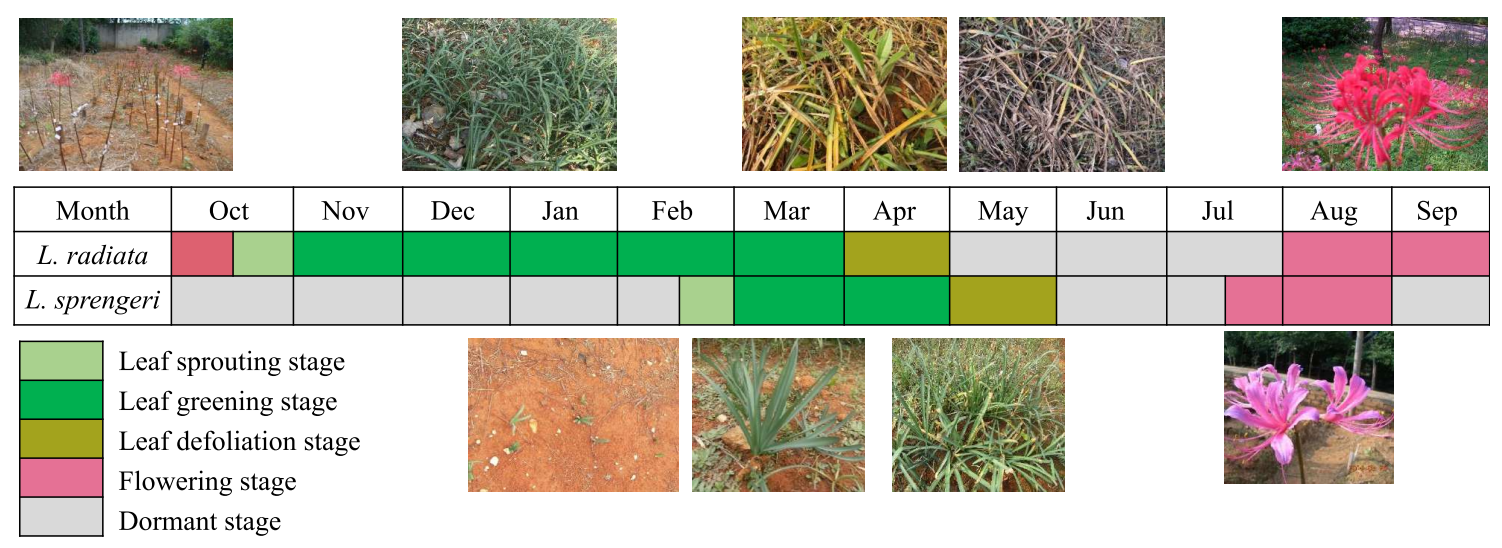

Fig. 1 Phenological photos of two species on the ground. 
environmental stress, such as high temperature in summer [9].

In all, a complete growth season of Lycoris plants includes the following stages (Fig. 1): leaf sprouting stage, leaf greening stage, leaf defoliation stage (leaf yellowing and withering), dormancy stage (leafless), and flowering stage (scape sprouting and blooming).

\section{Assessment of the anatomy during flower development}

The flower bud differentiation process of $L$. radiata can be divided into 8 stages (Fig. 2A-H): I. The meristem expansion preparatory period (early to late Mar; Fig. 2A); II. meristem expansion period (late to end of Mar; Fig. 2B); III. inflorescence and floret primordial formation period (early to midApr; Fig. 2C); IV. inner and outer perianth formation period (mid to end of Apr; Fig. 2D); V. stamen formation period (early to mid-May; Fig. 2E); VI. ovary formation period (mid to end of May; Fig. 2F); VII. pistil formation period (early to late Jun; Fig. 2G); VIII. anther and pollen formation period (from late Jun to early Jul; Fig. 2H) and then was the late flower development stage.

The flower bud differentiation process of L. sprengeri can also be divided into 8 stages (Fig. 2a-h): I. The meristem expansion preparatory period (late to end of Mar; Fig. 2a); II. meristem expansion period (from end of Mar to mid-Apr; Fig. 2b); III. inflorescence and floret primordial formation period (mid to late Apr; Fig. 2c); IV. inner and outer perianth formation period (late to end of Apr; Fig. 2d); V. stamen formation period (from end of Apr to early May; Fig. 2e); VI. ovary formation period (early to mid-May; Fig. 2f); VII. pistil formation (mid to end of May; Fig. 2g); VIII. anther and pollen formation period (from end of May to early Jun; Fig. $2 \mathrm{~h}$ ) and then was the late flower development period (mid-end of Jun).

The differentiation of $L$. radiata and $L$. sprengeri inflorescences shows apical dominance, and the differentiation sequence for simple flowers occurs from the outside to the inside. The flower bud differentiation processes of the two species are generally identical and can be divided into 8 periods. Overall, the flower bud differentiation process of $L$. sprengeri is faster than $L$. radiata. The late flower bud differentiation period for spring sprouting Lycoris plants is faster [10] and those flowering periods are also earlier mid- to late Jul).

We compared the phenology of these two kinds of Lycoris in the Nanchang area. The initiation of flower bud differentiation of $L$. sprengeri occurs during the leaf vigorous growth stage (Mar) and ends during the leaf wilt stage (late May). However, the initiation of flower bud differentiation of $L$. radiata takes place while the leaves are yellowing and ends during dormancy, across a longer time span.

\section{Physiological research on flower development}

Changes in soluble sugar and protein contents are intimately associated with plant growth and development. The seeds of Lycoris plants are rich in endosperm and store soluble sugar and starch [11]. The differences in soluble sugar and protein contents and oxidoreductase activity in $L$. radiata bulbs at different developmental stages are significant ( $p<0.0001$, Fig. 3).

Fig. 3 shows that the physiological changes during bulb flower bud differentiation in the two Lycoris species are similar. During stages I-IV, the soluble protein and soluble sugar content in $L$. sprengeri showed an overall increasing trend and peaked during stage IV, but the soluble protein content in L. radiata bulbs decreased. During stages V-VII, soluble protein contents showed a similar decreasing trend. This suggests that it not only needed to consume a large quantity of small molecule protein, but also rapidly accumulate a large amount of soluble sugar in the early stages (I-IV) of flower bud differentiation. Whereas in the late stages (VVIII), a large amount of energy (soluble sugar) and structural material (soluble protein) were directly consumed for flower organ formation.

However, there were significant differences in the physiological differentiation of flower buds in the two Lycoris species. First, throughout the flower bud differentiation process (stages I-VIII), the content of soluble sugar, soluble protein, and the activity of SOD in $L$. sprengeri bulbs were significantly higher than in L. radiata. However, the POD activity was lower. Second, the peak time of soluble sugar in $L$. sprengeri (mid-May) was nearly half a month later than that in $L$. radiata (late Apr). It shows that the physiological differentiation of flower buds in $L$. radiata starts earlier (end of Feb) than $L$. sprengeri (mid-Mar), and flower bud morphology formation and development (end of Jun) occurs later than L. sprengeri (early Jun). Flower bud differentiation in $L$. sprengeri is faster than $L$. radiata as the former requires 80 days and the latter requires 120 days. This may be because, in L. sprengeri, the leaves and senescence occur later, the leaves are bigger, and the photosynthetic efficiency is higher. 

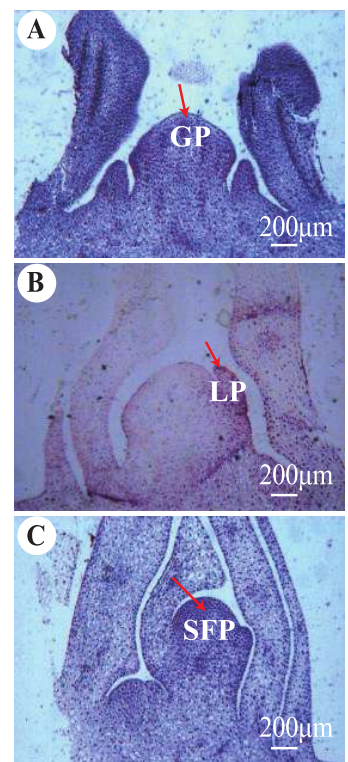

D
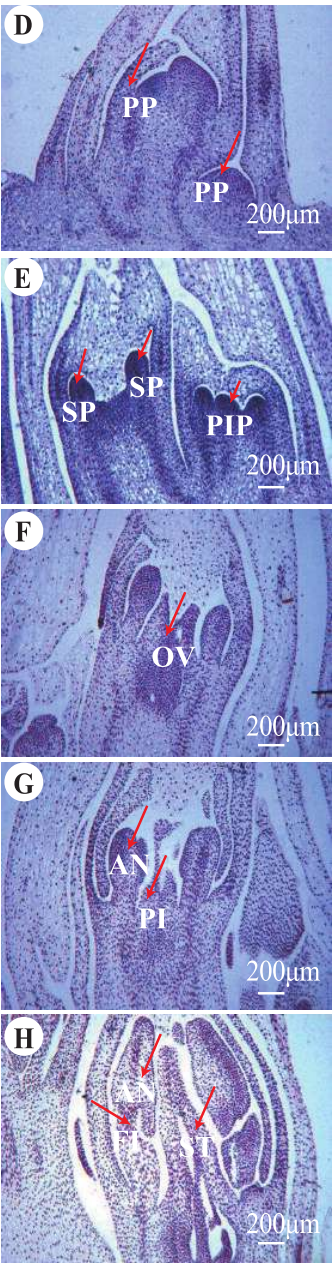
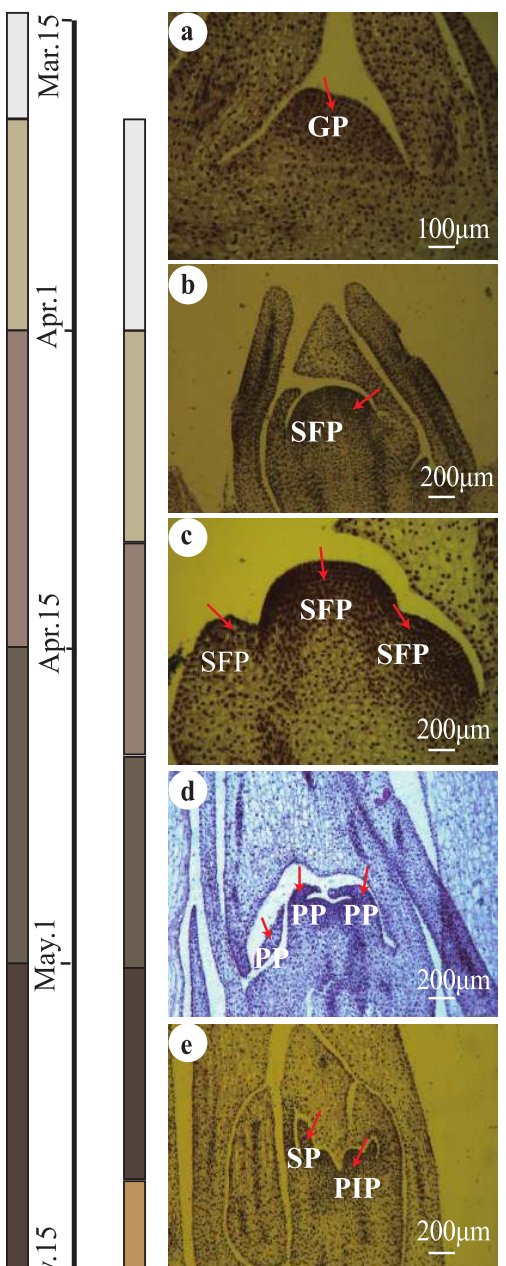

$\stackrel{n}{\stackrel{m}{\grave{m}}}$
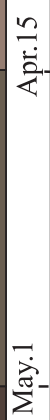
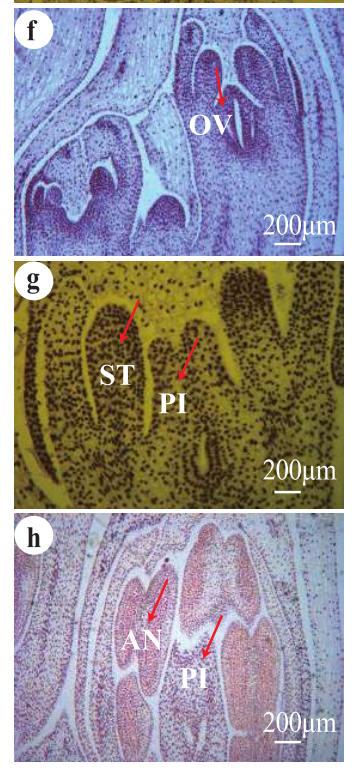

I: Meristem expansion preparatory period II: Meristem expansion period

III: Floret primordial formation period

IV: Perianth formation period

V: Stamen formation period

VI: Ovary formation period

VII: Pistil formation period

VIII:Anther and pollen formation period

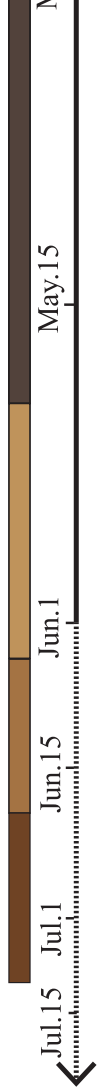

Fig. 2 (A,a) Meristem expansion preparatory period; (B,b) meristem expansion period; (C,c) floret primordial formation period; (D,d) perianth formation period; (E,e) stamen formation period; (F,f) ovary formation period; $(\mathrm{G}, \mathrm{g})$ pistil formation period; and $(\mathrm{H}, \mathrm{h})$ anther and pollen formation period. Fixing and straining were as described under Methods. 

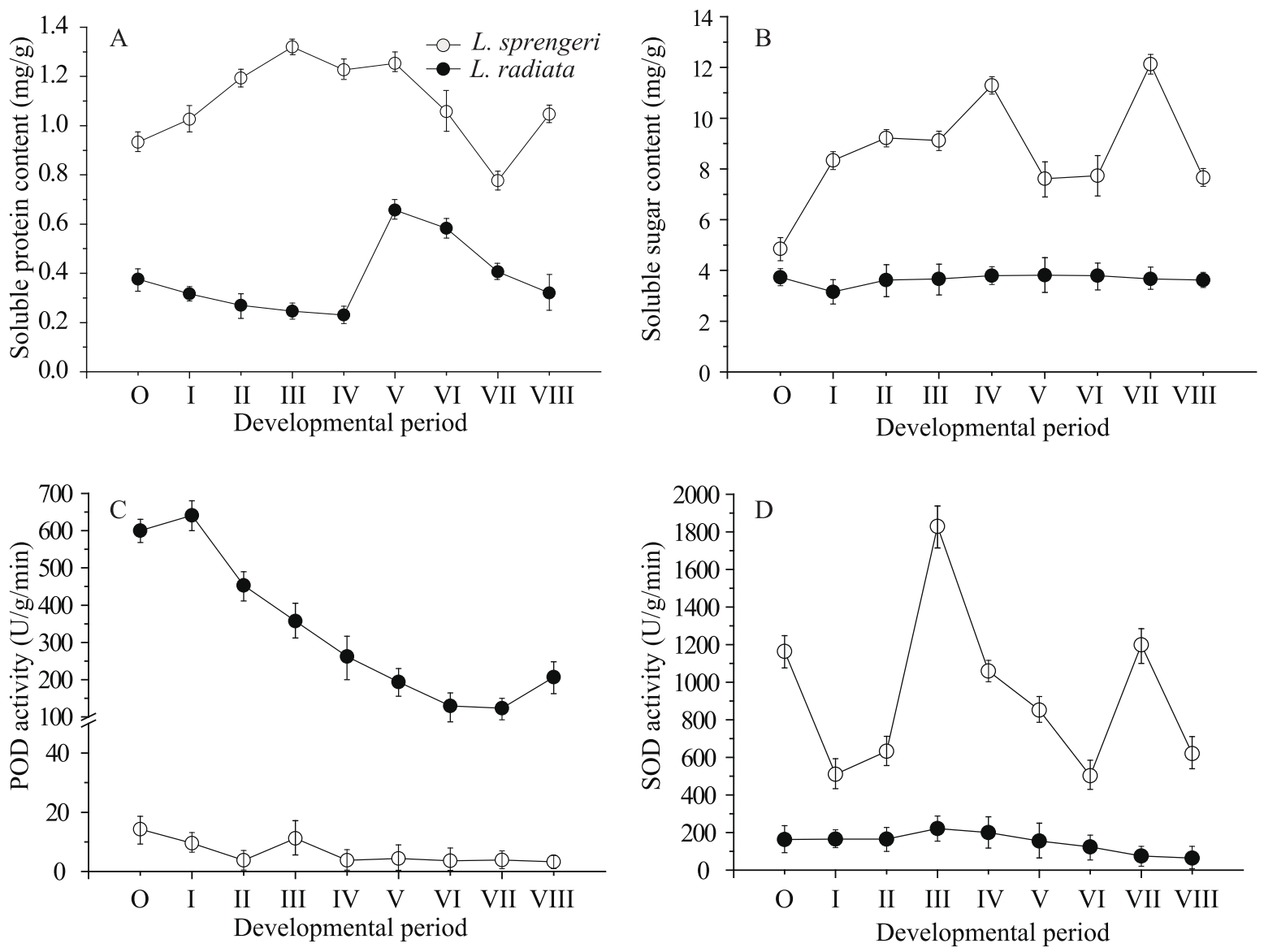

Fig. 3 Changes of the contents of soluble protein (A), soluble sugar (B), and activities of POD (C) and SOD (D) in bulbs of two Lycoris species at flower bud differentiation stage. O: Flower bud undifferentiated (before flower bud differentiation); I. flower bud differentiation preparatory period; II. floral primordium formation period; III. perianth lobe differentiation period; IV. stamen differentiation period; V. carpel formation period; VI. ovary formation; VII. pistil formation period; VIII. anther formation period.

\section{DISCUSSION}

\section{$L$. radiata and $L$. sprengeri have significantly different phenological characteristics}

The biological characteristics (i.e., leaf withering followed by dormancy and blooming in summer) of two Lycoris species were similar, but the phenological rhythm was considerably different. First, these species have different sprouting periods: $L$. radiata sprouts leaves in early Oct during autumn, while L. sprengeri sprouts leaves at the end of Feb during spring the following year. Second, these species have different leaf growth periods: The growth period of $L$. radiata leaves is from mid-Oct to early May and lasts for 7 months, whereas that of $L$. sprengeri leaves lasts for 3 months (i.e., early Mar to the end of May). Third, their flowering periods are different: the early flowering period of $L$. sprengeri is in Jul, and its full flowering period is in Aug. In contrast, the early flowering period of $L$. radiata is at the end of Aug, and its full flowering period is in Sep. Therefore, there are slight overlaps in the flowering period between the two species. Finally, their dormancy periods are different: $L$. radiata has nearly 100 days of dormancy before flowering (midMay to the end of Aug), but there is no or only a short dormancy period after flowering. Although the dormancy period of $L$. sprengeri before flowering is shorter (1 month), L. sprengeri has a 6-monthlong dormancy period after flowering (end of Aug to mid-Feb). The mean daily temperature required for $L$. sprengeri during the full flowering period is also higher than for L. radiata [12]. The setting percentage of interspecies hybrids is also lower, and the leaf sprouting time is generally identical to the parental plants [13]. 
In addition, leaf size (length and width), diameter of single florets, and mature bulb diameter of $L$. sprengeri are all larger than $L$. radiata. However, floral stem length and the number of florets in each inflorescence are smaller than $L$. radiata.

\section{Flower development is similar in these two species, but the rate of development is different}

Park et al [7] showed that the initiation time of flower bud differentiation of 5 species of Lycoris in South Korea lasted from Apr to early May, and the pollen formation of $L$. radiata took place last (Aug 18). It blooms from Sep-Oct, while the others bloom from Jul-Aug.

In the present study, the flower bud differentiation in both $L$. radiata and $L$. sprengeri occurs from Mar to May, and can be divided into 8 periods. Results also showed that the flower buds were preformed, i.e., the flower buds started differentiation before the leaves withered [4]. However, the process of flower bud differentiation was slightly faster in $L$. sprengeri than in $L$. radiata (starting late and ending early), which indicated that the late stage of flower bud differentiation (stamen and pistil differentiation stage) of spring-sprouting Lycoris plants was faster $[4,14]$, but the specific stage of division was not exactly the same [10]. The order of flower bud differentiation begins with apical development, and the differentiation of single bud takes place outside to inside [15]. Flower initiation in L. radiata occurs half a month earlier than in L. sprengeri, but the formation of flower buds in L. radiata occurs 20 days later. Because the floral organs of $L$. radiata require 2 more months of development than that of $L$. sprengeri. So $L$. radiata has a later flowering time than L. sprengeri. This may be due to differences in leaf size that correspond to photosynthetic efficiency. The length and width of $L$. sprengeri leaves is two-fold greater than that of L. radiata. A larger leaf area results in higher photosynthetic efficiency, a higher proportion of small starch particles [15] and only a short growth period is required to achieve nutrient accumulation, which accelerates flower bud differentiation.

\section{Flower bud differentiation in L. radiata and L. sprengeri has distinct physiological characteristics}

As a structural and energetic substance, protein (especially soluble protein) plays an important role in flower bud differentiation [16]. Starch and soluble sugar play important roles in maintaining the supply and demand balance of carbohydrates [17].
Starch is the main storage substance in bulbs, while carbohydrates are the metabolic resource for $L$. radiata flower bud differentiation and bulb development [18]. SOD and POD are anti-oxidant enzymes in plants that protect plants from damage by reactive oxygen species.

During the early to middle periods (I-IV) of flower bud differentiation, the soluble sugar content in $L$. radiata and $L$. sprengeri bulbs increased, whereas soluble protein content in L. radiata decreased. However, in the later flower bud differentiation periods (V-VIII), soluble sugar content in both species decreased, whereas soluble protein content increased. This shows that soluble sugar and soluble protein directly participate in flower development in $L$. radiata and L. sprengeri, and their levels represent the metabolic intensity or level or different stages of development in bulb plants to some extent. The result is similar to those of previous works performed in apple-pear fruit trees [15], but it differs from reports on lilies during their flower bud differentiation period, as bulb soluble protein content showed an overall increasing trend [19]. This may be due to the unique biological characteristics of Lycoris plants. This also shows that the main function of the bulbs at the early to middle stage of flower bud differentiation (I-IV) is to serve as a sink, whereas that in the later period (V-VIII) is to be the source. At the early flower bud differentiation period, a large amount of micromolecular proteins is required for morphological differentiation while simultaneously accumulating a large amount of energetic substances (carbohydrates). During the late bud differentiation period, as a large number of floral organ primordia are formed and developed, a large amount of directly usable energy (soluble sugars) and structural substances (soluble proteins) is consumed. The uneven distribution of starch grains in the bulb is also evidence of this source-sink relationship [20].

The two species also showed significant differences. First, the soluble sugar content of $L$. sprengeri peaked at different times (mid May), which is half a month later than that of $L$. radiata (late Apr). This may be because the leaf sprouting period of L. sprengeri is later, and the leaf growth period is shorter. Second, during the entire flower bud differentiation process, the levels of soluble sugar and soluble protein in $L$. sprengeri are significantly higher than $L$. radiata. Third, during flower bud differentiation, the POD activity of $L$. sprengeri was significantly lower than $L$. radiata, but the SOD activity is higher. POD is intimately associated with 
respiration, photosynthesis, and auxin oxidation and can be used as a physiological marker for tissue aging [21].

The flower bud differentiation in L. sprengeri occurs over the leaf flourishing period, maturation period, and withering period, whereas that in $L$. radiata occurs during the leaf withering period. However, the flower-bud differentiation process in L. sprengeri (80 days) was faster than that in $L$. radiata (more than 120 days). This is consistent with the significantly higher contents of soluble sugar, soluble protein, and SOD activity in the bulb of $L$. sprengeri than those of $L$. radiata. This is due to the larger and longer leaves of $L$. sprengeri and its higher net photosynthetic and water utilization rate [18] and the larger proportion of small starch grains (faster conversion into soluble sugar) in bulbs $[15,20]$.

It is generally believed that changes in soluble sugar content are a manifestation of carbohydrate supply and conversion [22]. Soluble sugars not only act as an energy source for the growth and development of Lycoris plants, but itself and its metabolites can also act as signaling factors that regulate genes that control plant growth and development [23]. A transcriptomics study showed that 2173 functional genes are involved in starch and sucrose metabolism [24]. The specific roles of soluble sugars and soluble proteins in the bulbs of Lycoris plants and their relationships require further investigation.

\section{CONCLUSION}

The annual growth cycle of Lycoris species usually has 5 stages: leaf sprouting stage, leaf greening stage, leaf defoliation stage (leaf yellowing and withering), dormancy stage (leafless), and flowering stage (scape sprouting and blooming). According to the pattern of flowering and leaf emergence, it can be divided into 2 types: L. sprengeri pattern and $L$. radiata pattern. The former sprouts leaves in early spring, blooms in summer, and has long dormant period after flowering (more than 120 days). The latter sprouts leaves after flowering in autumn and has short or almost no dormancy.

The flower bud differentiation process was similar in the 2 species, and it can be divided into 8 stages as follows: meristem expansion preparatory period, meristem expansion period, inflorescence and floret primordial formation period, perianth formation period, stamen formation period, ovary formation period, pistil formation period, anther and pollen formation period. However, the flower bud differentiation process of $L$. sprengeri was slightly faster than that of $L$. radiata, especially during the middle to late stage.

From the prophase to middle period of flower bud differentiation (I-IV), the soluble protein and the soluble sugar content in bulbs of $L$. sprengeri increased, while the soluble protein content in $\mathrm{L}$. radiata decreased. However, during the period of V-VII, the content of both substances decreased. In addition, throughout flower bud differentiation, the soluble sugar, soluble protein content, and SOD activity in the bulb of $L$. sprengeri were significantly higher than in that of $L$. radiata, but the peak time was half a month later.

Acknowledgements: This project was funded by the National Natural Science Foundation of China (Research on the phenomenon and mechanism of mosaic period non-meeting of $L$. radiata, 31560226).

\section{REFERENCES}

1. Hsu BS, Lin JZ, Yu ZZ, Huang SF (1986) Interspecific hybridization between Lycoris sprengeri and L. chinensis. Acta Hortic Sin 13, 280-281.

2. Zhang PC, Bao CS, Jiang Y (2015) Research advances on the biological characteristics of Lycoris and its cultivation techniques. Subtrop Plant Sci 44, 168-174.

3. Editorial Committee of Flora of China, CAS (2000) Flora of China24, Science Press, Beijing.

4. Liang SC, Shi CT (1992) Studies on induction and development of preformed floral buds in Lycoris aurea Herb. J Chin Soc Hortic Sci 38, 139-148.

5. Zhu CS, Xie SL (2008) Germplasm resources, medicinal exploitation of genus Lycoris and its rapid propagation. Jiangxi Forest Sci Technol 5, 41-42.

6. Wang Z, Li Y, Zheng YH, He SL, Peng F, Shu XC (2012) Anatomic observation of flower bud differentiation of Lycoris. Jiangsu Agric Sci 40, 155-157.

7. Park YJ, Park EH, Yoo SO, Chung YO (1991) Studies on the flower bud differentiation of the genus Lycoris native in Korea. $J$ Kor Soc Hort Sci 32, 545-550.

8. Zheng GC (1979) Biological Microscopy Techniques, People's Education Press, Beijing.

9. Chen XL, Liang Y, Qi W, Su M, Du GZ (2009) Studies on reproductive allocation, floral size and its tradeoff with floral number of annual Gentiana. Acta Pratacult Sin 18, 58-66.

10. Mori G, Imanishi H, Sakanishi Y (1990) Effect of temperature on flowing of Lycoris squamigera Maxim. and L. radiata Herb. J Jpn Soc Hortic Sci 59, 377-382.

11. Gong L, Wang HY, Yang YJ, Zhou J, Shao J (2010) Studies on seed characteristics and anatomic Structure of Lycoris chinensis. Seed 29, 10-16.

12. Wang L,Tang GG, Zhao JZ (2008) Study on flowering characteristics of 3 species of Lycoris. Jiangsu Agric Sci 1, 112-115. 
13. Jing M (2013) Study on crossbreeding of Lycoris and culture of the filial generation. Master thesis, Jiangxi Agricultural Univ, China.

14. Mori G, Sakanishi Y (1977) Studies on the growth and flowering of bulbous plants of Amaryllidaceae: 1. Growth and flowering of Lycoris plants grown in the field. J Jpn Soc Hortic Sci 45, 389-396.

15. Zhang ZJ, Wan TY, Zhen YH, Zhou J (2016) Study on distribution difference of starch particle size of different parts in 5 species of Lycoris (Amaryllidaceae). $J$ Anhui Agric Sci 44, 21-25.

16. Guo JL, Zhang YL (1999) A study on the metabolism of protein and during the of flower-bud differential starch of apple-pear fruit tree in the stage of flower bud differentiation. J Inner Mongolia Agric Univ (Nat Sci Edn) 20, 80-82.

17. Sun HM, Li TL, Li YF (2004) Starch metabolism and sprouting of bulb in Lilium davidii var. unicolor stored at different cold temperatures. Acta Hortic Sinica 31, 337-342.

18. Ou J, Lei DY, Yang Y (2011) Research on changes of carbohydrate metabolism and enzyme activity in high temperature treatment for (seed) bulbs of golden Lycoris. Seed 30, 36-39.

19. Tu SP, Mu D, Liu C (2005) The physiological and biochemical changes during flower bud differentiation of different Lily cultivars. Chin Agric Sci Bull 21, 207-209.

20. Shao J (2010) Basic study on accumulation and utilization of starch in bulbs of Lycoris. Master thesis, Nanjing Forestry Univ, China.

21. Huang SM, Zhang HB, Yu HZ (2017) Relation of the activities of SOD, POD, CAT and the content of MDA in leaf to grain-leaf ratio of rice. Hybrid Rice $32,76-80$.

22. Li XF, Wang Y, Deng XJ, Xiong LJ, Wu X (2009) Release of temperature, GA3 and ethylene to the dormancy of Chinese narcissus (Narcissus tazetta var. Chinensis Roem.). Plant Physiol Commun 45, 953-957.

23. Chang L, Chen JJ, Xiao MY, Xia YP (2011) De novo characterization Lycoris sprengeri transcriptome using illumina GAS. Afr J Biotechnol 10, 12147-12155.

24. Luckwill LC (1970) A new look at the process of fruit bud formation in apple. In: Physiology of Tree Crops, Academic Press, London, pp 237-254. 